\title{
Intellectual Disability in Children and Family Resilience: Clinical Case of Cameroonian Families
}

\section{Valdés Wamba Nguimabou* and Jacques-Philippe Tsala Tsala}

Psychology Department, Laboratory of Development and Mal-Development, University of Yaounde I, Cameroon

*Corresponding Author: Valdés Wamba Nguimabou, Psychology Department, Laboratory of Development and Mal-Development, University of Yaounde I, Cameroon.
Received: January 18, 2021

Published: March 11, 2021

(C) All rights are reserved by Valdés Wamba Nguimabou and Jacques-Philippe Tsala Tsala

\begin{abstract}
The situation of intellectual disability in children is becoming more and more visible and worrying in contemporary Cameroonian society. The announcement of this handicap, whether at birth or during the child's life, has an impact on family balance. It thus brings into play a family psychic transmission of suffering. The aim of this article is therefore to understand the process of resilience in these families confronted with intellectual disability in the Cameroonian cultural context. Inspired by the work of Frascarolo, Keren and Fivaz [1], then Osso [2] arising from the theory of family alliance, we formulated the hypothesis that a quality family alliance promotes resilience in Cameroonian families having a child with intellectual disabilities. The analysis of the data collected by means of the interviews, the family drawing test, and the Family Endurance Index (FHI) of Mc Cubbin, [3] show us that the announcement of the impairment engendered anxiety and a traumatic experience in all the families in this study. Also, a narcissistic parental injury has been observed and much more in mothers than in fathers. Both siblings and parents experience suffering following the deficiency of one of their own. Reorganization, the participation of all the members of the family, a more focused attention on the disabled child are visible in all families. This confirms our hypothesis on the quality of the family alliance as a factor facilitating resilience.
\end{abstract}

Keywords: Intellectual Disability; Family Resilience; Family Alliance; Clinical Case

\section{Introduction}

According to statistics from the World Health Organization [4], it is estimated that intellectual disability affects $3 \%$ of the population, or 156 million people worldwide. Almost $88 \%$ of these people have a mild intellectual disability, $7 \%$ have a moderate disability and only $5 \%$ a severe disability. In Cameroon, although there are no real statistics on intellectual disability, in the wake of currents of thought, political authorities and public opinion are changing the way they perceive children with disabilities. They are increasingly becoming the object of curative, psychological care, educational trials and special education.
Indeed, the announcement of a child's intellectual disability, whether at birth or during the child's first years, is often experienced by parents as a shock that will remain difficult to overcome (Quentel, [5]; Long and Marsland [6]; Korf-sausse [7]; Mulroy., et al. [8]; Ringler [9]. The occurrence of a disability within the family therefore generates anxiety due to the non-fulfillment of desire (Coppin [10]; Espagneul [11]; Scelles [12]; Marion., et al, [13]. The works of Tsala Tsala [14,15]; Emerson [16], Guyard [17], Mallangeau-Kianpisheh [18], Elhouda [19], emphasized the psychological modifications induced by the presence of the child with a disability in the family dynamic and quality of life, causing disturbances in 
fraternal bonds and in the individuation in construction of brothers and sisters, and this in little apparent suffering.

In African societies in general, it is accepted that unborn children represent a return to earthly life of spiritual principles from ancestors, or other humans, even geniuses or other non-human spirits Ezembé [20]; Moro, [21]. In front of such an approach which considers that the children come from the world of the ancestors, one can consider that the arrival of a deficient child is a form of reincarnation of evil spirits or is due to other supernatural causes. These authors evoked the death in new borns afflicted with significant organic diseases in traditional societies of South Cameroon, including autistic children. Lolo cited by Mbassa [22], observed the same phenomenon with autistic children in Cameroon, often considered as "children born to die". According to her, they do not want to stay in the world of the living and disturb the family dynamic by being born and dying several times.

The aforementioned works have highlighted the cultural representations of intellectual disability, the explanatory factors of family suffering, the involvement of siblings and parents in the management of disability or at least intellectual disability. It is following this problem that we became interested in the psychological mechanisms that these Cameroonian families put in place to be able to overcome adversity, in particular the deficiency of the child. Each family has its own way of being resilient and it sets up processes, some of which are directly observable, others not.

Intellectual disability: a complex reality

According to the World Health Organization, intellectual disability is the result of below average intellectual functioning and adjustment difficulties, which manifests itself before the age of 18 (the age representing the end of development). The expression "mental handicap" qualifies both an intellectual disability (scientific approach) and the consequences it entails on a daily basis (social and societal approach). Mental handicap therefore results in more or less significant difficulties in thinking, conceptualizing, communicating and making decisions.

Unlike mental handicap, psychic handicap can be defined as the social consequences (that is to say the limitations of activities and the restrictions of social participation) linked to a disabling mental disorder. It is associated with "psychiatric disorders, giving rise to behavioural damage and leading to the marginalization of the person (Charzat [22]). At the etiological level, three causes of intellectual disability are recognized, namely organic, psychological and environmental factors. Several common pathologies are associated with developmental disabilities. We can cite among others Trisomy 21, phenylketonuria, congenital hypothyroidism, Autism. In all cases of intellectual disability, successful treatment depends on early detection and early intervention. Since no specific etiology can be found in many cases and known causes cannot be cured in most cases, the goal of treatment is not to achieve "a cure" but to minimize symptoms and disability by reducing risk (for example, helping individuals to be safe at home and at school), teaching essential skills, improving quality of life, and supporting families and relatives.

Cameroonian family confronted with the intellectual disability of the child

The concept of disability is inseparable from the country, its level of development and the social context in which it is lived. In African societies, it is accepted that unborn children represent a return to earthly life of spiritual principles from ancestors, or other humans, or even geniuses or other non-human spirits. They are therefore considered strangers that parents must welcome, get to know, humanize and adopt. Thus, these children do not belong to the parent couple; they are singular individuals who, at the beginning, have more ties to the invisible world than the world of humans, as emphasized by Moro [21]. In front of such an approach which considers that the children come from the world of the ancestors, one can consider that the arrival of an intellectually deficient child is due to the reincarnation of evil spirits or to other supernatural causes. Thus, some deficient children may be doomed to abandonment.

According to Ezembe [20], the representations of the disease differ between cultures. Another example, linked to beliefs about the disease and which comes up often in the literature, concerns the conceptions of different parts of the body and their role in nosology. Thus: "The Beti of Cameroon considered the heart as the seat of intelligence, the alienated man is a man without intelligence, mental alienation is therefore considered as a heart disease". Thus, it is clear that the cultural system is a whole with its own logic according to each society. It thus conditions all behaviour in medical matters. In the current context, in Cameroon, three currents dominate the

Citation: Valdés Wamba Nguimabou and Jacques-Philippe Tsala Tsala. "Intellectual Disability in Children and Family Resilience: Clinical Case of Cameroonian Families". Acta Scientific Medical Sciences 5.4 (2021): 48-61. 
sphere of care: traditional medicine, the cultural heritage of Africans, medicine of Western origin, considered official medicine, and spiritual treatment through churches. He already evoked the death of new-borns afflicted with important organic pathologies in the traditional societies of South Cameroon, among whom the autistic children. According to her, they do not want to stay in the world of the living and disturb the family dynamic by being born and dying several times. Parents perceive them as inhabited by an evil spirit, therefore threatening. Thus, among the "Bafias" of central Cameroon, to put an end to their incessant journeys between the world of ancestors and that of human beings, the parents are subjected to a traditional psychodrama during which several domestic animals are sacrificed (sheep or goats), puppies, chickens, etc.). The healer marks the child's body with a sign by scarification (usually on an exposed and easily spotted part such as the face) so that it is recognized and identified immediately if it is reborn. He does this by uttering incantations inviting the ancestors to keep him with them permanently. To the latter, the officiant asks not to come into the world again if he does not want to remain among men.

According to a well-organized ritual, these are sent back to the river or the river. The same considerations were observed among the "Bafias" in central Cameroon, where children with multiple disabilities (severely disabled cerebral palsy) were considered as bringing bad luck and representing a threat to the family and the community. Let us specify that family morality is social morality Ezembe [20].

We have collected the speeches of the participants of our study, in particular those of the "Bamilékés" of the West region and "Sawa" of the Cameroon littoral region on intellectual disability in children in order to better understand it in its socio-cultural context. Among the Bamileke "Yemba" of West Cameroon, expressions such as: "Té Pon Môh" are used to designate these children who are sick from birth and different from others. Thus, the deficient child is perceived as having "water in the head", "stones in the head", a "hard head" hence his slowness in understanding the messages and tasks transmitted to him. In "Sawa" in the region of Littoral, they talk about "Di Biyé lé Esougou mo" to describe these children whose reflection is short. And on a cultural level, the deficiency would result from a generational transgression, from a committed fault, hence the expressions "moubé ma ba s'ango basu ô moya bana basu na tena nyoon ii tanu". Among the "Bafias" of central Cameroon, some people are considered to be "epilepsy throwers or throwers", the cause of intellectual disability in children.

According to De Rosny [24], "the therapeutic space is a delimited environment so that the patient's relational and emotional universe moves symbolically. In Africa, this framework has always been a traditional space in an agrarian cultural context, generally delimited by a fence or branches which have the property of protecting. This traditional space has exploded under the influence of urbanization which disrupts the traditional symbolism". That said, faced with the intrusion of the disease or faced with a disorganizing trauma, African families in Africa first and almost always opt for the traditional health care system (healers, marabouts, prayer groups) for indigenous diseases and this. It's only when healing is slow in coming that they will then in desperation try something else. In view of this course, it would be a therapeutic triangle on the front of the sharing of the therapeutic space in a complementarity of skills, instead of "round care", because each step corresponds to a specific objective sought. that only one therapist can bring him in his competence. Only this "inter-therapeutic" or intercultural approach allows him to reconstruct his multiple fissured identities. A sort of "therapeutic pluralism". Faced with such an inter-therapeutic approach, each therapist would benefit from adopting an intercultural approach instead of positioning themselves as a "goanywhere" therapist at the risk of being disqualified.

\section{From trauma to the process of family resilience}

Freud [25] initially favored the rise of sexual arousal to define the trauma with reference to the clinic of hysteria. It is important to specify that for there to be trauma, it is necessary that the excited subject, under tension, be unable to use his possibilities of mental elaboration of the event and in the impossibility of having recourse to more archaic pathways of flow, discharge of excitement (bodily and behavioural pathways). Freud's initial definition assumes that it is not the event in itself that is traumatic but the inability to integrate it at an intra-subjective level, a point of view that we also find in Marty [26] and Lemay [27]. From an economic point of view, the trauma is directly linked to an excess of excitement not treatable by the subject.

Ferenczi's [28] theory brings an additional element by suggesting that we should focus on the consequences of trauma, in this case the affects of unpleasure that it arouses, mainly affects 
of anxiety, depressive and aggressive such as anger and rage, the elaboration of which is no longer possible. From this, we p ouvons hypothesize that the resilient individual is the one who will manage to regulate negative affect triggered by adverse events without being overwhelmed. The role of defense mechanisms is recognized by several specialists in this field although they are not psychoanalytic. These include, among other things, cleavage, denial, intellectualization, humor (Cyrulnick [29], Vanistendael-Lecomte [30]). All of these defence mechanisms should be seen as so many intrapsychic devices capable of promoting resilience whenever the subject is confronted with too much excitement that is a source of intense displeasure. As such, they constitute an important protective factor for the ego. It is also necessary to evaluate with precision the flexible or rigid use made of it by the subject. In children, we will generally speak of resilience when there remains, despite an unfavorable environment, a capacity to do basic learning and to socialize without showing too much inhibition and / or instability. The AngloSaxons also invite us to reflect on the mechanisms and processes which are the protective factors in the individual that are the basis of his resilience. The conceptualization that we are going to develop now on the relations between the quality of the family alliance and resilience seems to us capable of fully meeting this objective.

\section{Material and Method}

For exploratory purposes, we conducted this research with two families with a child with intellectual disabilities followed at the "Center for Specialized Rehabilitation the Renaissance" call now "Educ-Rehab Foundation" in Yaoundé, Cameroon. Semi-structured interviews associated with the family endurance index [3] and the family drawing test were used as data collection tools. These collected data were then analyzed using the content analysis technique for family interviews and statistical analysis for the endurance index.

\section{Results and Discussion}

We present ons here the results from the semi-structured interviews with the families of the study and a comparison of these results to the theory will allow us to assess the relevance.

\section{Yohann's family}

History

Yohann, 10 years old and the second child of five siblings, is a child who does not present a problem on the physical level. Walk- ing and grip are good. However, there is stuttering in the language. Very hyperactive, he presents a delay in schooling given his age. Yohann is a smiling boy and moreover very participative in any type of work so asks him to achieve; even if he doesn't know how to do it, he still tries unlike many of his friends. At first glance, it is difficult to know that the latter presents some difficulties. He sometimes shows low self-esteem (especially when he is criticized), is also agitated too much which results in giving up what he does, Loses concentration regularly.

\section{Disclosure of impairment}

The announcement of Yohann's deficiency was made when he was 03 years old by the doctor who did not fail to point out that the etiology of his disease would result from a complication during his birth. The father expresses himself: "In fact it was when he was 3 years old that the doctor told us that he has had a complication since birth. It's a problem that will gradually improve... it was not easy at the beginning all the time he was having seizures and we had to go to the hospital..." After this announcement, the family experienced an upheaval and a reorganization. This is also the case of the mother who after this diagnosis will have to reconcile professional occupations and care for her child. This is what the father expresses "My wife had to leave her job to be close to him because we had to watch all the time".

The announcement of the child's disability generated a narcissistic parental wound. "We had this news like a bomb in our family. She followed all her appointments before the birth. She had problems during the delivery because the child was not coming out. But the doctors said after that it was ok, on the contrary it was the beginning of the suffering". The mother adds: "as my husband just said this news came to destabilize us. We didn't understand anything. For me the mother I received it as a punishment... I kept asking myself how it happened and why my dear child".

\section{Care management}

The management of the anxieties linked to the child's disability was not easy for the mother. In order to find a solution to her child's problem, the latter undertook several therapeutic steps: "When I think about that day I have tears in my eyes, we saw almost everyone. Neuropediatrician at the Chantale Biya Foundation, the speech therapist because he did not speak, the physiotherapist for massages all the time, here at the rehabilitation center there is 
the psychomotor therapist and the psychologist. Really we haven't seen who?".

Originally from West Cameroon, Yohann's parents used traditional medicine. This approach to traditional care can be explained by the representation that most of the inhabitants of this region have of the child's illness. "Hmm yes, without lying to you, we even went to the village to see. I am Bamileke and with us this kind of child they say that they often came from elsewhere, sometimes it is the demons, or then the bad people who want to take him".

These representations vis-à-vis the child's illness have led the mother to adopt behaviors that she herself describes as unorthodox because it puts the life of her child at risk: "Even over there it didn't. nothing given he is still there... you imagine that I left this child outside at midnight because I was told that he is a baby snake and he will transform (lower his head, low intonation, tear in eyes). My poor man remained crying on the cold... really I wish it and my marriage almost ended after that".

\section{Family experience of intellectual disability}

Yohann's disability has generated anxieties within his family and consequently conflicts. The father's experience: "Everyone was sad to see him suffer like this. But we still had hope. The two families even entered into conflict because of the accusations on the left and on the right... We have waited a long time for this baby it is the first one you imagine if you are expecting a child and he arrives sick how do you feel ? It's not easy to live with that...".

After enormous design difficulties, the birth of Yohann was received by both great families with great joy. Joy which quickly turned into sadness after diagnosis of the deficiency. The mother's experience: "My husband didn't say everything. In fact I even had a lot of conception problems at first before this baby came (...) so when I knew I was pregnant it was total joy in my family. And after the sadness as he is sick (...)". The mother seems more resilient nowadays thanks to the status of the other children she has been able to bring into the world despite the difficulties of known conception "Today it's okay anyway we do with as we can (...) the others are well".

\section{The experience of siblings}

Within Yohann's family is Jeanne, who occupies a very important place thanks to the role of second mother she plays with him.
Like the parents, she has difficulty living the suffering of Yohann whom she considers as her own child.

Cousin Jeanne 27 years old expresses himself "he is like my child because I have been next to him for years. As his mother had to go back to work because she had left, I came to stay with them and I take care of him...."

\section{Understanding of Yohann's emotions and states by Jeanne}

Jeanne tries as much as possible to understand Yohann's emotions and mental state in order to adapt and be able to communicate better with him: "I understood that he is retarded and I got used to his delay. I speak he understands and even when he wants to say things to me I understand a little by dint of staying with him. He is very nice and doesn't bother... "You just have to avoid making him get angry because when he starts crying he doesn't stop and afterwards it's malaria".

\section{Family reorganization}

The mother expresses herself: "Now it's even going a little. At first it was serious I couldn't do anything. You had to be with him all the time. No one could stand what he was doing. (Sadness) I even left my activities to stay with him. My husband sometimes came home to help me. When I gave birth to his little sister, his cousin Jeanne had to come and stay with us to take care of him".

\section{Understanding of one's mental state and that of others}

The father recognizes his mental states, emotions and those of others. He gives meaning to the mental states of children, notably Jeanne and those of his wife, while recognizing the evolving character of these states and emotions over time: "As you see Jeanne there, it is thanks to her that we understand our child well. She also suffered a lot because it was she who spent more time with him... my wife as the mother of the child it is very normal that she suffers from time to time but I think she is calmer and less stressed today. It even shows she has a smile or before it was all gone... she dresses well and everything. She was getting weird".

The same is true of his mental states. Giving meaning to the representations of relatives and family members who had their origin in cultural beliefs, the father of Yohann imagines behaviors and states mentau x current: "As for me I admit that at first I did not feel not too much, but afterwards I was very uncomfortable. You understand the friends, brothers and all the family were looking at 
me like I walked somewhere. I am a little calmer today even as I am still reflecting on what will become of him".

The mother recognizes and does not feel the emotions of the father: "I understood my husband from the start. Men cannot feel the same because it is we carry these children in the womb for months and after delivery we take care of them while the men are outside...".

\section{Parents' handling of adversity}

Yohann's mother affirms that they are doing their best to cope with the situation despite the still-present difficulties: “(...) If I tell you that it's really okay I'm not telling the truth. Even as the others are well it always hurts to see a different child. And in addition he is more turbulent. So there are discussions all the time, but compared to before I'm not too sad anymore. Except when he is sick (...) his father, like all men, remains positive. To overcome this, we sometimes avoid talking too much about it (...) Bon is no longer really united more than before except the bad tongues from outside".

The father for his part recognizes the suffering of the mother who remains present despite the time and the efforts they provide: "For me it's okay all the same but for the same it's a woman she pretends in front of the children but I see that she still suffers a little. When sometimes she asks what the child will become when he grows up... with sadness it means that she is worried. And that's normal (...)".

\section{Commentary on Yohann's family drawing}

Yohann, 10 years old and male, is the second of five siblings. Regarding the composition of the family drawn, Yohann reproduces all the members of his family in an orderly fashion (from father to mother, then children according to their age). His drawing shows an identification with the father. All family members are represented in Yohann's drawing. This shows that he is aware of the family environment in which he lives.

Regarding the overall aspects, it maintains the sheet as presented by the examiner with an even distribution (balanced and organized drawing). All characters drawn with overall use of space on the sheet.

Yohann's drawing is made in continuous, big lines, with blanks on the characters. We also note an erasure during the production of the second character, in particular the mother. Clinically, he would express a more pronounced emotional investment in the latter given the time taken to draw this character unlike the others. It is the same for the overall size (Mother $10,3 \mathrm{~cm}$ and $8.8 \mathrm{~cm}$ Father) which would explain this maternal emotional investment.

Regarding the layout elements, we note a global alignment of the right drawing (less than or equal to $15^{\circ}$ ), with characters not distant from each other. The silhouette is presented from the front. The characters in Yohann's drawing are represented by age and generations ranging from father, mother and children according to their rank in the family. This shows that despite the disability, he manages to imagine his family environment and is aware of the nature of the interactions, of the links between the members of the said family.

During its reproduction, it insists on the maternal figure. The mother's perseverance when drawing Yohann is an expression of her attachment and emotional investment in her. Also, we note elements of regression. By the age of 10 , the body pattern should already be acquired in the child. But we note that all the characters in his drawing have neither ears nor feet despite the space present on the drawing sheet. Clinically, this would be the expression either of castration linked to his awareness of his handicap, or the expression of a relational conflict. The Polychromy of colors with a mixture of hot and cold colors and a predominance of intense colors (yellow, red, blue, lime green) would also be an explanatory factor of this conflict and aggressiveness. No kinesthetic element is represented, nor verbalized by the subject and for symmetry, we note a minor problem. The parts of the body are not adequately represented and this in all the characters in Yohann's drawing. Some (Fabiola and Fortune) have erasures during the production of the head. Aggression is manifested when breeding sisters Fabiola and Fortune. On the other hand, an expression of a slight smile can be perceptible through the faces of other members of the family.

The detailed aspects bring out similar details for each character and when it comes to identity elements Yohann's design brings out the differences through the hair. This represents a good development of identity in the child although the body diagram is not completely reproduced. The real family is reproduced this shows that the child manages to imagine the people around him. We don't notice any real closeness between family members through Yohann's 
drawing. The identification elements are present in particular the hair (father-Yohann and mother-sisters).

Resilience assessment results (Yohann's family)

\begin{tabular}{|c|c|c|c|c|c|c|}
\hline \multirow{2}{*}{$\begin{array}{c}\text { Yohann's } \\
\text { family }\end{array}$} & $\begin{array}{c}\text { Global } \\
\text { FHI }\end{array}$ & $\begin{array}{c}\text { FHI- } \\
\text { mother }\end{array}$ & $\begin{array}{c}\text { FHI- } \\
\text { father }\end{array}$ & FHI-Eng & $\begin{array}{c}\text { FHI- } \\
\text { chal }\end{array}$ & $\begin{array}{c}\text { FHI- } \\
\text { control }\end{array}$ \\
\cline { 2 - 7 } & 1.37 & 1.2 & 1.55 & 1.75 & 1.0 & 1.06 \\
\hline
\end{tabular}

Table 1: Family endurance index : Yohann's family. FHI = Family endurance index ; Chal $=$ Challenge ; Eng $=$ Commitment $;$ Control $=$ Control .

\section{Comment}

After analyzing the speech following the interviews, the Yohann family shows an average capacity for resilience. With regard to belief systems, we observe a good current capacity of parents to be able to overcome and make sense of adversity, in particular the deficiency of the child. Family members have a positive attitude towards disability and a moderate tendency towards spirituality. Regarding organizational bosses, a strong family flexibility is observed, with interdependence, average economic and social resources. As for the communication within the family system, it is very good, the emotions are shared with clarity in the communication between the parents.

The evaluation of family resilience through the Family Endurance Index (FHI) reveals that the Yohann family has a low resilience capacity with a score below the average, ie $1.37 / 3$. We note a good average resilience of the father (1.55) compared to the mother (1.2). In general, the family has a good capacity for commitment in the management of difficulties (1.75/3) with insufficient control of adversity (1.06/3) and enormous difficulties to overcome (1/3).

Nicole's family

History

Born by induced delivery at 11 months of pregnancy, Nicole did not present the birth cry. But after sweeping, the cry was present. However, it should be noted that her mother had a water loss at 11 months of pregnancy. She experienced growth problems at 6 months after birth, feeding problem at 1 year 7 months, refusal to latch on the mother's breast, accelerated heartbeat. Nicole at 2 years old already presented some difficulties on the motor level, a problem of schooling due to the completely absent language. A problem of anality expressed by its inability to acquire cleanliness habits, a problem of self-assertion (it remained harmless to others). She ate soft foods at home. This is not the case at the rehabilitation center. Also, interactions with other children at the center show a withdrawal into oneself. Fine motor skills are not yet present, which is why some passive behaviors are observed in their interactions.

Announcement of the diagnosis of deficiency in children

The diagnosis of the deficiency in Nicole was made gradually. It is at the age of one and a half that the doctor announces to them that the child has a development problem and specifically Autism.

"We waited a year and a half before knowing anything, we had an appointment every Friday and each time they had something new to tell us. Each time I was more anxious... She went to the hospital three times a week (...). With the diagnosis from the other hospital it was okay, but she still has symptoms. I even went to see the Foundation's neuro-pediatrician (...)" says the mother.

\section{The shock of the announcement}

The news of Nicole's disability came as a shock to the parents although the mother after the birth of the child was already seeing signs. "It was the very shock because we did not expect it at all. Right after the birth, I saw his eyes and recognized the Mongolian. But we weren't told. They waited for us to ask... I don't even know how to take time for myself, I'm not used to it anymore. Some days are heavier than others".

\section{Therapeutic route}

Although Nicole's parents opted for an orientation towards modern medicine as soon as Autism in children was announced, a resort to the traditional was also present because of the cultural representations of these symptoms in the context of "Boulou". The parents are from the Central Cameroon region.

"We started with the hospital because the doctor told us it's Autism... well we didn't even know what it is. She has a problem with walking, she does not speak at the same time, hmmm (lowers her head; low voice) she had everything except what a child of her age must have (...) we are bored my husband and me and at home we are told that the kind of children there are complicated so you have to go see people who see far and take care of that. We went to see them and nothing has changed". 


\section{Interactions within the family system}

The interactions between parents and between parents and children are without particularities, however, given that the African family is larger and is based on grandparents, uncles, aunts, in-laws, etc. we see relationship conflict. This conflict would arise from the cause attributed to the handicap of the child within the large family.

"With my husband we had no problem. Hmmm (loud voice, expression of anger, change of sitting position) but with my in-laws it was serious. I am a trader and I fight with all my strength for something. As my child came when my business and catering activities were going well we said everything... ooh I sold the child for my money. Hmmm really whereas the other children have nothing and besides she is not the only one (...) God only knows the truth in the illness of my child (...). She plays well with her brothers and with us and above all I understand more and more what she wants".

\section{Family reorganization}

After diagnosis of the deficiency in the child, a reorganization within the family framework is inevitable. Nicole's parents, both very busy with their jobs, experienced great difficulty because they now needed someone who was constantly close to the child. As in most families the mother's first attachment figure is most concerned. Nicole's mother speaks: "My husband is very busy, very tired from his work. I worked from 2 p.m. to 8 p.m. sometimes 9 p.m. when there are clients. But it's a hellish schedule (...) hmm it wasn't easy, someone between us had to leave his job. I had no choice, you had to be close to him all the time while waiting for things to change (...)".

Nicole's family benefits from the support of relatives and entourage for the monitoring of children given their situation. This has a lot to do with their balance: "We have a lot of people to turn to, so as not to always ask the same ones, for example to look after the children. But we also make many more requests because we also have to take care (...)".

A parent gives meaning to the mental states of other members

The father gives meaning to his mental states and recognizes the evolving character of these states in relation to the behavior of the child: “(....) But hey we'll do with it. In fact at the beginning it was difficult to understand but now we understand all the same... for my wife I understand that she is really affected even today her behavior shows that she suffers sometimes. It's normal humm in his place it's not easy especially them women (...) for me it is going before as I did not understand where it comes from I thought otherwise. Today to do with (...) in fact in my family everyone who is close to Nicole felt very bad. His sister, me, my wife and today, good things are going to be fine because every day she changes anyway and we are reassured (...)".

The mother also imagines her mental states and those of her husband: "hmm (breathes hard, smile) if I tell you that I did not think negatively about what I was wrong about myself. I was lost at the beginning by his illness, the world had fallen on us, in short I was very bad (...) my husband also suffered but not like me it was sure... after each one gave themselves and today it's okay all the same... with time the wounds heal and life goes on (...)".

Much more, Nicole's mother imagines Nicole's mental states. She understands what lives in her by reflecting to him emotions similar to hers: "We make the effort that our little sister helps him at home when they learn and often she is aggressive with her, maybe she thinks that it is. is that we bring it down. And when she does that it makes me sad. It's not her fault she's sick and sometimes seeing her sisters doing things and her not makes her sad. Hmmm she is very clever. When she does something that is not right and she knows that we are going to get angry, she becomes sad (...) even when I sometimes cry because of her, she also cries next to me. It means that she is sad, she feels what I feel (...)".

\section{Parents' handling of adversity}

The mother expresses a positive attitude and a good family capacity to overcome adversity: "With the other children, it's fine. By grace everything will be fine for her. I accept that she is different but she can do something. In the center she makes a lot of efforts and that really reassures us (smile, normal voice)".

"To tell you the truth, it is because we are believers and we have understood that it is not the end of the world to have a child who is delayed (...) we give her everything so that she is happy like the others". Says the father.

\section{Commentary on nicole's drawing}

Aged 07 and the first of three siblings, Nicole reproduces a family made up of her, her little sister, then her mother. The drawing of

Citation: Valdés Wamba Nguimabou and Jacques-Philippe Tsala Tsala. "Intellectual Disability in Children and Family Resilience: Clinical Case of Cameroonian Families". Acta Scientific Medical Sciences 5.4 (2021): 48-61. 
Nicole presents omissions in particular the father, and the younger sister. And she identifies with the mother. The absence of the paternal fig and the use of identifying elements, particularly the hair, in the figures expresses an identification with the mother. Regarding the overall aspects, it maintains the sheet as presented by the examiner with an even distribution (balanced and organized drawing). The characters are drawn using the top left space of the sheet with a face silhouette.

Although the location of Nicole's drawing follows the proposed format, we observe an imbalance in the reproduction and composition of the characters drawn. Its drawing is oriented to the top-left. Clinically, this refers to the expression of a more or less conflictual family relationship, marked by the conflict with the unreproduced father (father less invested in the emotional relationship) and also the little sister.

The degree of accomplishment of her drawing is more or less good because we are missing Cindy in her drawing and missing body parts (ears, arms, feet) in all the characters. The line is made in broken lines, big, parts in white, erasures with dirty appearance. On the clinical level, it would express an affective disorder and an aggressiveness. Regarding the arrangement of the characters, we note a straight alignment, with a distance from the mother to the two children reproduced, and a particular order (going from the children to the mother). With the mother, we note more perseverance given the time taken during the drawing and the elements of differentiation (emphasis on clothing and accessories).

A major regression can be seen through Nicole's drawing. This manifests itself through fragmented parts and scotomization. Because although there is space on the sheet, characters are omitted. These regressive tendencies would be the expression of an affectivity experienced negatively within her family system (she develops a Cain complex vis-à-vis her little sister not reproduced).

No movement is represented and as elements of symmetry, we note an absence of ears, arms and legs in the children drawn or present in the mother; beauty accessories for the mother (glasses, earrings, high shoes, flowers in the hand). The time taken as well as the insistence on the elements of beauty in the mother figure is an expression of beauty and cheerfulness in the latter. Also, incomplete representation in children is a manifestation of aggres- siveness vis-à-vis the living environment. The child projects here a desire to identify with the mother whom she idealizes. After an overall depiction of the mother with $8 \mathrm{~cm}$ height, $2.2 \mathrm{~cm}$ head, $1.5 \mathrm{~cm}$ trunk, $2 \mathrm{~cm}$ arms and $2.5 \mathrm{~cm}$ legs, she uses a mixture of warm colors and cold and a predominance of intense colors (lime green, blue) to express it.

Regarding identity elements, we note the hair for female identification, as well as women's shoes, glasses, flowers in the hands of the mother. Although characters are omitted in the drawing, Nicole reproduces her actual family. We observe a closeness between Nicole and her little sister (expression a good relationship).

\begin{tabular}{|c|c|c|c|c|c|c|}
\hline \multirow{2}{*}{$\begin{array}{c}\text { Nicole's } \\
\text { Family }\end{array}$} & $\begin{array}{c}\text { Global } \\
\text { FHI }\end{array}$ & $\begin{array}{c}\text { FHI- } \\
\text { mother }\end{array}$ & $\begin{array}{c}\text { FHI- } \\
\text { father }\end{array}$ & FHI-Eng & FHI-chal & $\begin{array}{c}\text { FHI- } \\
\text { control }\end{array}$ \\
\cline { 2 - 7 } & 1.85 & 1.7 & 2.0 & 2.33 & 1.44 & 2.0 \\
\hline
\end{tabular}

Table 2: Family endurance Index: Nicole's family. FHI = Family endurance index; Chal = Challenge; Eng $=$ Commitment; Control $=$ Control .

\section{Comment}

After analyzing the speech following the interviews, Nicole's family with regard to belief systems has an average ability to cope with adversity, a fairly positive attitude towards Nicole's disability and a fairly pronounced tendency towards transcendence and spirituality. Although there is a strong interdependence, we note an average family flexibility with average economic and social resources. We note collaborative problem solving, emotions are shared between members and communication is present with moderate clarity.

The evaluation of family resilience through the Family Endurance Index (FHI) reveals that the Nicole family has a good capacity for resilience with an above-average score of 1.85/3. A greater capacity for resilience in the father (2.0) than in the mother (1.7). And with regard to the sub-items of the family endurance scale namely persistent difficulties (challenges), family engagement in problem solving and control of difficulties that members of the system face, we observe a strong family tendency towards controlling adversity (2.0) and a collaborative commitment (2.33) for managing difficulties although challenges are always present (1.44). This shows the need for assistance for high family resilience.

Citation: Valdés Wamba Nguimabou and Jacques-Philippe Tsala Tsala. "Intellectual Disability in Children and Family Resilience: Clinical Case of Cameroonian Families". Acta Scientific Medical Sciences 5.4 (2021): 48-61. 


\section{Discussion}

Speaking of family alliance, the concept was developed by FivazDepeursinge [31] from the level of coordination between the supervising system and the supervised system. More particularly, this concept corresponds to the capacity of the family to coordinate and create a favorable context of communication within the system. This ability allows the family to coordinate to complete a task. We consider that the family alliance is revealing of the functioning of the family, since it highlights different aspects of communication within the family. Reiss (1989), cited by Favez, Frascarolo, Keren and Fivaz [1] affirms that the family regulates the development and the psychological well-being of the child through the coordinated practices of all the members. The family alliance is based on four functions of interaction of the relationship of family members. These are four dimensions constituting the structural aspects of interactions: participation, organization of roles, focused attention and emotional contact.

In the traditional African universe, life is conceived as a mating or at least as an endlessly renewed childbirth since the world is perceived as divided into two parts: one male and the other female. In such a process of continuous creation, man is the image of the law which is the expression of the word of the ancestors. The woman is the living bridge between the visible and invisible worlds, especially as it is the rebirth of spring ancestor as the child's birth and the e renewal of the clan (Sow [32]; Hebga [33]). That said, the birth of the intellectually deficient child would lead to a failure in the rebirth of the ancestor and consequently a rupture of ties. Faced with this traumatic situation, families have recourse to a symbolic universe which allows a defensive arrangement in relation to the culture. The family alliance in question here will therefore be understood in its link to cultural realities.

In order to be able to face adversity effectively, parents need to perceive a real involvement of all members of the family system. This allows a sharing of tasks, a collective search for solutions to the needs of the disabled child and those of other members of the family, and also a sharing of emotions in the face of adversity. That said, participation implies a reorganization and sharing of roles so that the weight of suffering is not centered on the mother (the child's primary object of attachment), but on all the members. The families of Yohann and Nicole are accountable for this participation of all members of the family system.
Reorganization within the family system refers to the sharing of roles and the nature of support from both family members and the home community. The analysis of the cases shows us that the placement of the child in a Rehabilitation Center at an early stage allowed the latter to quickly acquire skills, and the parents of the psychoeducation sessions allowed them to better understand the handicap and to reorganize. their family system. Men who are generally less involved in care are more and more so, which facilitates family resilience. In Yohann's family, for example, family reorganization and the involvement of all members facilitate the management of anxieties among members and strengthen family ties.

The families in this study due to the child's disability all develop a more focused attention on the child. Faced with the suffering of the child, the quality of the relationship and the attention of the parents are essential for the balance of all the family system. In addition, parents of children with disabilities often express their loneliness in the face of the many difficulties they face.

\section{Conclusion}

Through a clinical approach, we have grasped the process of resilience in Cameroonian families with a child with intellectual disabilities. Work on the family alliance $[1,2]$ served as a theoretical frame of reference. The results of this study show that following the announcement of the deficiency in the child, the members of the family system go through a period of anxiety. The therapeutic route adopted by Cameroonian families is linked to their representations of disability in children and to cultural requirements. Participation, family reorganization, focused attention on all members facilitate the process of resilience within families. Further research on communication techniques in clinical interviews with children with intellectual disabilities whether severe, moderate or mild will be of capital importance to better understand their perception and point of view, but also to facilitate their involvement in the process. family resilience. In research, it is essential to take into account the point of view of people living with an intellectual disability in order to know their perceptions and the issues that concern them. The importance of opting for the use of 'participatory' type research methodologies, in which people have the opportunity to express their opinion about their living conditions, is emphasized by many authors (Emerson [16]). Guillemette and Boisvert [34]) already spoke of clinical interviews with people with intellectual disabilities. In addition to interviews, games and drawings can serve as 
communication tools with these children with intellectual disabilities. It would therefore be interesting to see essential that the staff, parents and relatives of the child with disabilities are capable of these approaches. At the practical level, we plan to help integrate it in Cameroon with the help of institutions in charge of children with disabilities, cells of psychological help for assisted resilience for these families It should be noted that similar services already exist in the European context with therapeutic approaches based on mentalization (Debbamé [35]). Their particularity in our context will reside in the taking into account of cultural factors, as Mayi [36] already underlined in all their diversity and originality. Con- clusion should reflect and elucidate how the results correspond to the study presented and provide a concise explanation of the allegation of the findings.

\section{Conflict of interest}

No conflict of interest and $\mathrm{p}$ have funding for this research.

Appendix: Index of family endurance (Family hardiness index)

Decide if you disagree, somewhat disagree, somewhat agree or agree with the statements listed below.

In our family...

\begin{tabular}{|c|c|c|c|c|}
\hline Items & At variance & Somewhat disagree & Somewhat agree & okay \\
\hline 1. Our problems are the result of the mistakes we make. & & & & \\
\hline $\begin{array}{l}\text { 2. ... It is unreasonable to plan ahead or to hope, because } \\
\text { nothing materializes anyway. }\end{array}$ & & & & \\
\hline $\begin{array}{l}\text { 3. ... Our work and efforts go unrecognized, no matter } \\
\text { how small the effort. }\end{array}$ & & & & \\
\hline $\begin{array}{l}\text { 4. ... In the long run, the bad things that happen to us are } \\
\text { balanced by the good ones. }\end{array}$ & & & & \\
\hline $\begin{array}{l}\text { 5. ... We feel like we are strong even when we face big } \\
\text { problems. }\end{array}$ & & & & \\
\hline $\begin{array}{l}\text { 6. ... Often I have the feeling that even in difficult times } \\
\text { things will work out. }\end{array}$ & & & & \\
\hline $\begin{array}{l}\text { 7. ... Although we may not always agree, we can count on } \\
\text { each other to support us when needed. }\end{array}$ & & & & \\
\hline $\begin{array}{l}\text { 8. ... We don't think we can survive if a new problem hits } \\
\text { us. }\end{array}$ & & & & \\
\hline $\begin{array}{l}\text { 9. ... We believe that things will work out for the best if we } \\
\text { work together as a family. }\end{array}$ & & & & \\
\hline 10. .... Life seems boring and meaningless. & & & & \\
\hline $\begin{array}{l}\text { 11. ... We fight together and we help each other no matter } \\
\text { what. }\end{array}$ & & & & \\
\hline $\begin{array}{l}\text { 12. ... When we do family activity plans, we try new and } \\
\text { exciting things. }\end{array}$ & & & & \\
\hline $\begin{array}{l}\text { 13. ... We listen to each other's problems, wounds and } \\
\text { fears. }\end{array}$ & & & & \\
\hline $\begin{array}{l}\text { 14.... we tend to do the same things over and over again... } \\
\text { it's boring. }\end{array}$ & & & & \\
\hline $\begin{array}{l}\text { 15.... we encourage each other to try new things and } \\
\text { experiences. }\end{array}$ & & & & \\
\hline
\end{tabular}




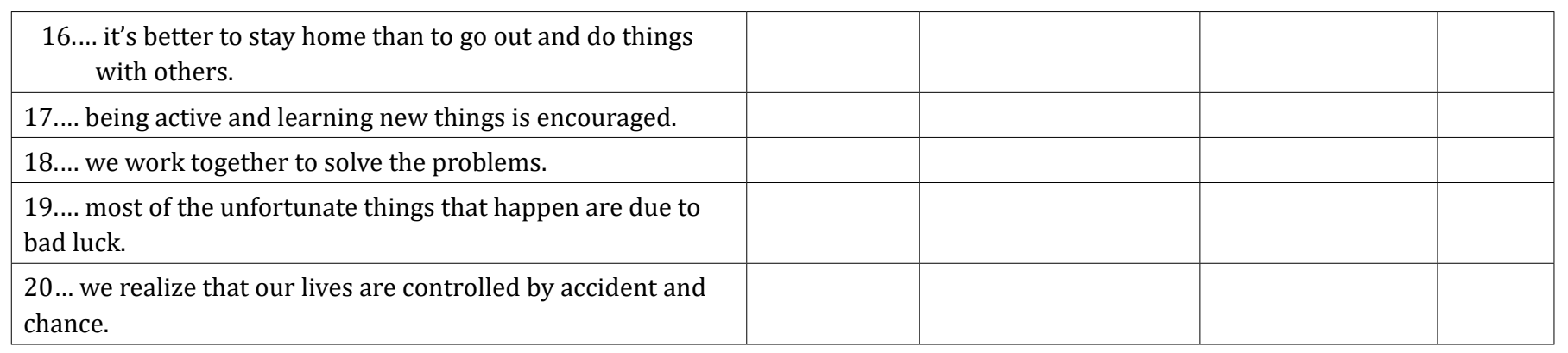

Table a

Annex: Family drawing

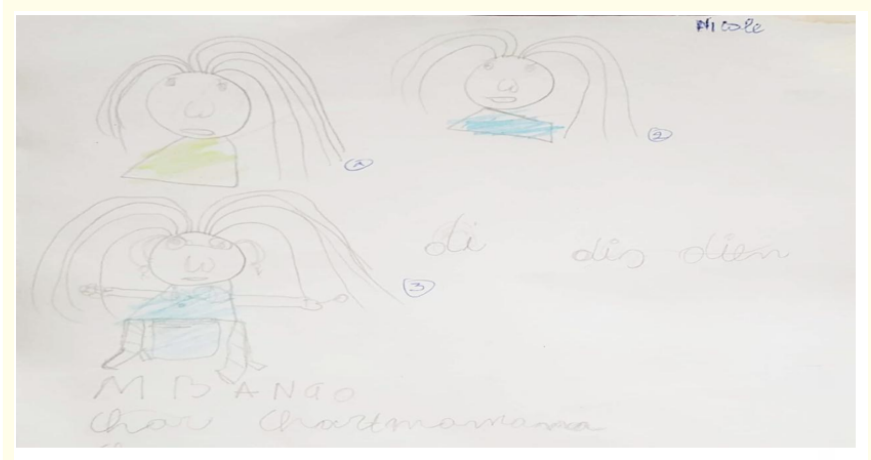

Figure a: Nicole's family drawing.

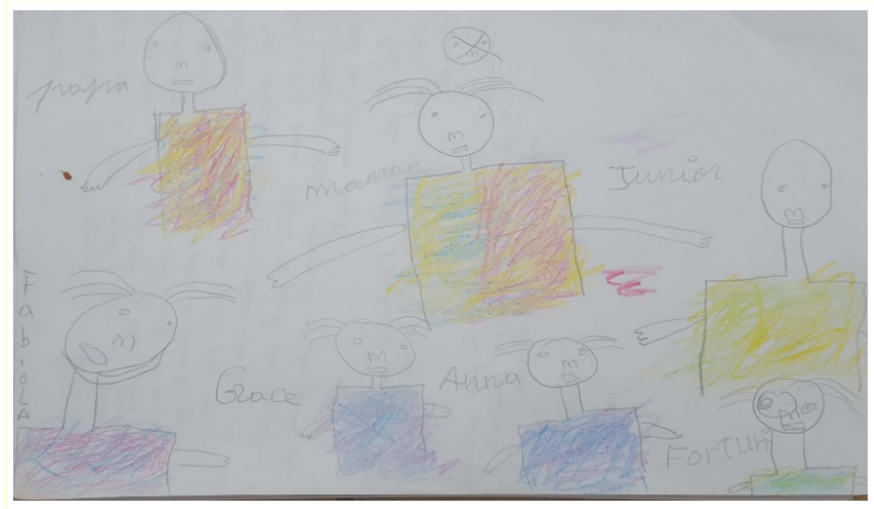

Figure b: Drawing Family Yohanna.

\section{Bibliography}

1. Frascarolo F and Favez N. "A new situation to assess family functioning: The Picnic game". Becoming 17.2 (2005): 141151.

2. Osso C. "Triadic mentalization and its link with family interactions between mother, father and child: preliminary results". Masters: University. Geneva (2011).

3. McCubbin MA and McCubbin HI. "Families coping with illness: The Resiliency Model of Family Stress and Adaptation". In C. Danielson, B. Hamel-Bissel and P. Winstead-Fry (Eds.) Families, health, and illness: Perspectives on coping and intervention. St. Louis, MO (1989).

4. WHO. "World Report on Disability" (2011).

5. Quentel JC. "From responsibility to guilt. The example of parents of disabled children". Regards Clinique 229 (1999): 1-34.

6. Long KA and Marsland AL. "Family adjustment to childhood cancer: A systematic review". Clinical Child and Family Psychology Review 14 (2011): 57-88.

7. Korff-sausse S. The impact of disability on parenting processes, in Reliance: review of disability situations, education and societies, file: The family to the test of disability, ${ }^{\circ} 26$, ed. Ramonville Saint-Agne: Erès (2007): 22-29.

8. Mulroy S., et al. "The impact of having a sibling with an intellectual disability: Parental perspectives in two disorders". Journal of Intellectual Disability Research 52.3 (2008): 216-229.

9. Ringler M. "Understanding the disabled child and his family". Paris: Dunod (2004). 
10. Coppin B. "Being a parent with an intellectual disability". ERES, Contrast 22 (2005): 285- 314.

11. Espagneul M. "On the proper use of the concept of "mourning for the ideal child", in Reliance: review of disability situations, education and societies, file: The family to the test of disability, $n{ }^{\circ} 26$, ed. Ramonville Saint-Agne: erès (2007): 44.

12. Scelles R. "The process of resilience in families with a child with a disability". In F. Marty (dir.) Figures and treatment of trauma. Paris: Dunod (2001): 173-184.

13. Marion G., et al. "Parental perception of the repercussions of a child's disability on siblings". Family Therapy, Geneva 31.2 (2010): 167-179.

14. Tsala Tsala JP. "Family Secret and Contemporary African Family Clinic". Journal of Psychoanalytic Family Therapy, The Family Divan 19 (2007): 31-45.

15. Tsala Tsala JP. "Spoken madness or intellectual disability through the beti proverbs of South Cameroon". Cahiers de sociologie économique et culturelle 29 (1998): 101-109.

16. Emerson E. "Mothers of children and adolescents with intellectual disability: social and economic situation, mental health status, and the self-assessed social and psychological impact of the child's difficulties". Journal of Intellectual and Developmental Disability 47 (2003): 385-99.

17. Guyard A. "Impact of the child's handicap on family life". Doctoral thesis. University of Grenoble (2012).

18. Mallangeau-Kianpisheh MJ. "Family mediation as a resource for parents facing the handicap of their child". Childhood and Adolescent Neuropsychiatry 62 (2014): 226-234.

19. Elhouda FN. The quality of life of parents of children with disabilities in the Fès Meknes region. Doctoral thesis in medicine. No. 166/18. Mohamed Ben Abdellah University. Morocco (2018).

20. Ezembe F. "Representations of illness and care". The African Child and His Universes (2009): 211-245.

21. Moro MR. "Example of cultural logics". In MR Moro, Growing up in a transcultural situation. Brussels: Fabert (2010).
22. Mbassa M. "Social and cultural representations of children's disability in black Africa”. Perspectives 54 (2015): 30-43.

23. Charzat M. "To better identify the difficulties of people with disabilities due to mental disorders and the means to improve their lives and that of their loved ones". Paris: Ministry of Employment and Solidarity (2002).

24. From Rosny E. The new African healers: reorganization of the therapeutic space". In Delachaux and Nestlé (Eds), Basic texts in psychology (1992): 248-267.

25. Freud A. "The ego and defense mechanisms". Paris: PUF (1976).

26. Marty P. Mentalization and psychosomatics. Paris: The "Preventers from going round in circles", Ulysse (1991).

27. Lemay M. Reflections on resilience, in "Suffrir but build oneself" by MF Poilpot (dir). Toulouse, Eres (1999): 83-105.

28. Ferenczi S. "Reflections on trauma". in Psychoanalysis 4 (1934): 134-147.

29. Cyrulnik B. "The murmur of ghosts". Paris, France: Edition Odile Jacob. Daily, DK, Ardinger, HH, Holmes, GE (2000). Identification and evaluation of mental retardation. American Family Physician 61 (2003): 1059-1067.

30. Vanistendael S and Lecomte J. "Happiness is always possible: building resilience". Paris: Bayard (2000).

31. Fivaz-Depeursinge E., et al. "Framing development, the systemic point of view. Educational, parental, therapeutic functions". In Critical Papers of Family Therapy and Networking Practices 4-5 (1982): 63-74.

32. Sow I. "The anthropological structures of madness in black Africa”. Paris, France: Payot (1978).

33. Hebga MP. “Witchcraft: Dangerous Chimera?” Abidjan, Inades (1979).

34. Guillemette F and Boisvert D. "The qualitative research interview with adults with intellectual disabilities". Qualitative Research 23 (2003): 15-26.

35. Debbamé M. "Mentalize. From theory to practice”. Crossroads psychotherapy. Deboeck, superior (2018). 
Intellectual Disability in Children and Family Resilience: Clinical Case of Cameroonian Families

36. Mayi MB. "Four essays in African psychopathology". Paris, France: Dianoïa (2017).

\section{Assets from publication with us}

- Prompt Acknowledgement after receiving the article

- Thorough Double blinded peer review

- Rapid Publication

- Issue of Publication Certificate

- High visibility of your Published work

Website: www.actascientific.com/

Submit Article: www.actascientific.com/submission.php

Email us: editor@actascientific.com

Contact us: +919182824667 